CZU: 634.8

https://doi.org/10.53082/1857-3142.21.85.05

\section{Afinitatea de altoire a unor soiuri autohtone de vită-de-vie Vitis vinifera, altoite pe diferite soiuri de portaltoi aflate în cultură în Republica Moldova}

Simion UNGUREANU, doctor în științe agricole, https://orcid.org/0000-0003-2122-4962; email: vierul_isphta@mail.ru;

Dmitrii MIHOV, doctor în științe agricole, https://orcid.org/0000-0003-0652-3710; email:dmytrii@gmail.com;

Institutul Ştiinţifico-Practic de Horticultură şi Tehnologii Alimentare;

Vasile VUTCARĂU, director general, SRL „Elvitis-Com”, https://orcid.org/0000-0002-8727-6565

Rezumat. În lucrare sunt prezentate rezultatele cercetărilor privind stabilirea afinității de altoire a unor soiuri autohtone vitis vinifera altoite pe 3 soiuri de portaltoi. Cel mai înalt randament de material săditor din soiurile Fetească neagră și Codrinschi au fost obținute prin altoirea lor pe portaltoiul 10114, iar pe soiurile Fetească regală și Rară neagră respectiv pe portaltoiurile Kober 5BB și SO4.

Cuvinte-cheie: afinitate, butași, altoi, portaltoi, vițe altoite, forțare, călire.

Abstract. The paper presents the results of studies on the determination the graft affinity of some local (aboriginal) grape varieties grafted on 3 rootstock varieties. The highest yield of planting material was obtained on varieties Feteasca Neagra, Kodrinsky, grafted on rootstock 101-14, and the variety Feteasca Regală, and Rara Neagre on rootstock Kober 5BB, SO4.

Keywords: affinity, cuttings, scion, rootstock, grafted seedlings, excavation, acclimatization.

\section{INTRODUCERE}

Una dintre condiţiile de bază care trebuie luată în considerare la alegerea soiurilor de portaltoi este afinitatea lor cu soiurile producătoare de struguri. Numai printr-o afinitate bună între altoi şi portaltoi se pot obţine viţe altoite cu concreştere completă, longevitate înaltă şi de productivitate sporită.

Spectrul larg al influenţei sub care se manifestă afinitatea dintre altoi şi portaltoi a dus la subîmpărţirea acesteia în afinitatea morfologică şi afinitatea fiziologică [3], afinitatea de altoire şi afinitatea de producţie [14]. Afinitatea de altoire reprezintă o con- diţie de bază în producerea materialului săditor viticol, în timp ce afinitatea de producţie este o cerinţă importantă ce se impune la înfiinţarea noilor plantaţii de vii moderne de lungă durată, cu recolte maxime de calitate superioară de struguri.

Numeroasele cercetări ştiinţifice $[1,6,9,8]$ au demonstrat cu prisosinţă că în cazul altoirii viţei-devie are loc o influenţă reciprocă a partenerilor altoiţi. Portaltoiul exercită o influenţă puternică asupra creşterii [2, 4,] fertilităţii [5], rezistenţei la secetă, la temperaturi minime, a productivităţii $[7,11,12,13]$, precum şi a potenţialului oenologic [10].

E de remarcat faptul că lucrările de specialitate efectuate în ultimii ani cuprind numeroase informaţii privind afinitatea de producţie a soiurilor Vitis vinifera, cum ar fi: Chardonnay, Traminer, Cabernet-Sauvignon, Merlot, Aligote, Sauvignon, Riesling, Pinot noir, şi a unor soiuri de selecţie nouă: Viorica, Riton, Leana, lalovenschi ustoicivîi, Muscat de laloveni, Kişmiş lucistîi ş. a. [10, 12, 13].

Însă cercetări ştiinţifice privind stabilirea celor mai corespunzătoare soiuri de portaltoi pentru altoirea soiurilor autohtone Vitis vinifera (Fetească neagră, Fetească regală, Rară neagră, Codrinschi ş a.) nu s-au efectuat mai mult de 50 de ani, deși soiurile enumerate şi clonele din aceste soiuri sunt mai bine acomodate la condiţiile climatice din R. Moldova (suportă mai bine temperaturile minime din timpul iernii) şi asigură producţii înalte de struguri de calitate superioară.

Erorile comise în urma alegerii incorecte a soiurilor de portaltoi pentru altoirea soiurilor viţei-devie producătoare de struguri nu pot fi corectate. În consecință, scade productivitatea, se reduce rezistența butucilor la cloroză, secetă şi temperaturi minime, ceea ce provoacă ulterior apariţia golurilor. Ca rezultat, se constată pieirea prematură a plantaţiilor viticole.

Deci, stabilirea celor mai corespunzătore soiuri de portaltoi pentru altoirea soiurilor autohtone Vitis vinifera producătoare de struguri prezintă una dintre principalele probleme ale dezvoltării cât mai eficiente a viticulturii. Aceasta justifică actualitatea cercetărilor privind stabilirea afinităţii de altoire şi a afinităţii de producţie a soiurilor autohtone şi de selecţie nouă altoite pe diferite soiuri de portaltoi.

\section{MATERIALE ȘI METODE DE CERCETARE}

Cercetările au inclus organizarea variantelor din experienţă în care s-au luat în calcul doi factori esenţiali: soiurile altoi şi soiurile portaltoi. În acest scop s-au utilizat 4 soiuri autohtone: Fetească neagră, Fetească regală, Rară neagră şi Codrinschi - soi de viţă nobilă, creat în cadrul Institutului de Viticultură şi Vinificaţie din Republica Moldova de către amelioratorul Valentina Vedeneeva, prin încrucişarea soiului 
Rară neagră cu soiul Cabernet-Sauvignon. Soiurile de altoi menţionate au fost altoite pe 3 soiuri de portaltoi raionate în Republica Moldova: Riparia x Rupestris 101-14 cl. 3, Berlandieri x Riparia Kober 5BB cl. 114 şi Berlandieri x Riparia SO4 cl. 5. Cu cele 4 soiuri altoi Vitis vinifera şi 3 soiuri de portaltoi experienţa a fost constituită din 12 variante altoi/portaltoi.

Producerea materialului săditor altoit a fost efectuată în pepinierele SRL „Elvitis-Com” şi „Retrodex”.

Forţarea butaşilor altoiţi a fost efectuată prin metoda cu stratificarea totală cu rumeguş şi încălzire exterioară, precum şi prin metoda forţării butaşilor cu baza în apă.

Plantarea butaşilor în şcoala de viţe s-a efectuat în biloane ridicate din primăvară şi acoperite cu peliculă neagră din polietilenă, sub care a fost plasat un furtun pentru irigarea prin picurare.

Pentru determinarea afinităţii de altoire, după forţarea şi călirea butaşilor altoiţi s-a urmărit cu deosebire formarea calusului circular la punctul de altoire, pornirea în creştere a lăstarilor de pe altoi şi formarea rădăcinilor la baza portaltoiului. După recoltarea viţelor din şcoala de viţe s-a urmărit, pe fiecare variantă a experienţei, randamentul şi calitatea materialului săditor.

\section{REZULTATE ȘI DISCUȚII}

Prin determinările efectuate, după forţarea şi călirea butaşilor altoiţi, au fost obţinute datele experimen- tale prezentate în tabelul 1, care denotă că media numărului de butaşi altoiţi cu calus circular la punctul de altoire, la toate soiurile producătoare de struguri luate în cercetare, a fost mai mare în cazul altoirii lor pe portaltoiurile Riparia x Rupestris 101-14 (97,2\%) şi Berlandieri x Riparia Kober 5BB $(88,4 \%)$, iar la butaşii altoiţi pe portaltoiul Berlandieri x Riparia SO4, indicele de calusare a fost mai mic şi a constituit $87,9 \%$.

Calitatea biologică a butaşilor altoiţi depinde nu numai de capacitatea formării calusului pe secţiunile componentelor altoirilor, dar şi, în mare măsură, de pornirea în creştere a ochilor de pe altoi în timpul forţării şi călirii. Pornirea în creştere a ochilor în timpul forţării butaşilor altoiţi este influenţată de soiul portaltoi folosit la altoire. În primul rând se pornesc în creştere ochii de pe butaşii altoiţi pe portaltoiul 101-14, urmat, peste 3-4 zile, de pe butaşii altoiţi pe portaltoiul Kober 5BB, şi numai peste 2-3 zile după pornirea în creştere a ochilor de pe butaşii altoiţi pe portaltoiul Kober 5BB încep a creşte ochii de pe butaşii altoiţi pe portaltoiul SO4.

După călire, înainte de plantare în şcoala de viţe, numărul butaşilor cu lăstari din altoi porniţi în creştere, la toate soiurile producătoare de struguri, a fost mai mare în cazul utilizării la altoire a portaltoiului 101-14 (91,8\%), urmat de Kober 5BB (84,4\%), iar mai mic - pe portaltoiul SO4 (82,5\%).

Sub aspectul formării rădăcinilor la baza butaşilor altoiţi după călire înainte de plantare în şcoala de viţe, s-au obţinut date experimentale care demon-

\section{Datele obținute în urma forțării și călirii butasilor din soiurile autohtone vitis vinifera altóite ṕe diferite soiuri de portaltoi (SRL „Elvitis-Com" și SRL „Retrodex", media 2015- 2020)}

\begin{tabular}{|c|c|c|c|c|}
\hline \multirow{2}{*}{ Soiul altoi } & \multicolumn{3}{|c|}{ Soiul portaltoi } & \multirow[b]{2}{*}{ Media } \\
\hline & $101-14$ & Kober 5BB & SO4 & \\
\hline \multicolumn{5}{|c|}{ 1. Butaşi cu calus circular la punctul de altoire, $\%$} \\
\hline Fetească neagră & 96,3 & 86,7 & 87,9 & 90,3 \\
\hline Fetească regală & 98,6 & 81,7 & 88,0 & 86,1 \\
\hline Rară neagră & $\overline{98,7}$ & 83,1 & 96,7 & 91,5 \\
\hline Codrinschi & 100 & 100 & 90,0 & 96,7 \\
\hline Media & 97,2 & 88,4 & 87,9 & 91,2 \\
\hline \multicolumn{5}{|c|}{ 2. Butaşi cu lăstari din altoi porniţi în creştere, $\%$} \\
\hline Fetească neagră & 90,6 & 87,7 & 81,8 & 86,7 \\
\hline Fetească regală & $\overline{86,6}$ & 76,7 & 75,2 & 79,5 \\
\hline Rară neagră & 89,8 & 78,2 & 82,8 & 83,6 \\
\hline Codrinschi & 100 & 95,0 & 90,0 & 95,0 \\
\hline Media & 91,8 & 84,4 & 82,5 & 86,2 \\
\hline \multicolumn{5}{|c|}{ 3. Butaşi cu rădăcini la baza portaltoiului, după călire, $\%$} \\
\hline Fetească neagră & 68,5 & 27,8 & 19,1 & 38,5 \\
\hline Fetească regală & 54,0 & 21,1 & 14,6 & 29,9 \\
\hline Rară neagră & 68,5 & 28,1 & 26,2 & 40,9 \\
\hline Media & 63,7 & 25,7 & 20,0 & 36,5 \\
\hline
\end{tabular}


strează că soiul de portaltoi şi metoda de forţare determină durata perioadei de formare a rădăcinilor, precum şi numărul butaşilor cu rădăcini.

În primul rând, apariţia rădăcinilor s-a înregistrat pe butaşii altoiţi pe portaltoiul 101-14, iar apariţia rădăcinilor pe butaşii altoiţi pe Kober 5BB s-a produs cu 5-7 zile mai târziu faţă de pe cei altoiţi pe 101-14, cel mai târziu au apărut rădăcinile pe butaşii altoiţi pe portaltoiul SO4.

Numărul de butaşi cu rădăcini, la toate soiurile producătoare de struguri, a oscilat în funcţie de soiul portaltoi utilizat la altoire. Procentul de butaşi altoiţi cu rădăcini la bază, înainte de plantare în şcoala de viţe, la toate soiurile luate în cercetare, a fost superior $(63,7 \%)$ în variantele în care s-a utilizat la altoire portaltoiul 101-14. În cazul în care la altoire s-a folosit soiul de portaltoi Kober 5BB, înainte de plantare în şcoala de viţe, s-au înregistrat 25,7\% de butaşi cu rădăcini. Cel mai mic număr de butaşi cu rădăcini, în medie la toate soiurile producătoare de struguri $(20,0 \%)$, s-a înregistrat pe butaşii altoiţi pe portaltoiul SO4.

E de remarcat faptul că şi prin aplicarea metodei de forţare în apă a butaşilor altoiţi pe soiurile de portaltoi cu perioada îndelungată de apariţie a rădăcinilor se pot obţine rezultate bune, însă numai în cazul aplicării anumitor procedee tehnologice, şi anume: înainte de altoire, partea bazală a butaşilor de portaltoi trebuie supusă preforţării timp de 4-6 zile în mediu umed, la temperatura de $20-22^{\circ} \mathrm{C}$.

În timpul forţării în apă a butaşilor altoiţi e necesar de creat condiţii de aeraţie a bazei butaşilor (pentru o anumită perioadă de timp), prin evacuarea apei din lăzi sau containere, lăsând butaşii altoiţi la forţare fără apă la bază, timp de 10-12 ore, apoi în lăzi sau containere se va turna apă proaspătă (un strat nu mai gros de $4-5 \mathrm{~cm}$ ), acest procedeu e necesar de repetat la forţare şi călire peste fiecare 2-3 zile. Procedeele propuse contribuie la grăbirea apariţiei rădăcinilor pe butaşi.

Criteriul de bază care determină stabilirea afinităţii de altoire este randamentul şi calitatea viţelor altoite. Datele prezentate în tabelul 2 confirmă că la interacţiunea combinată altoi/portaltoi au dat cele mai bune rezultate soiurile Codrinschi $(58,3 \%)$ şi Fetească neagră $(56,3 \%)$, altoite pe soiul de portaltoi 101-14, iar soiul Fetească regală - pe portaltoiul Kober 5BB (54,9\%). Cel mai scăzut randament, în medie pe toate combinaţiile altoi/portaltoi, s-a înregistrat la soiurile Rară neagră $(33,3 \%)$ şi la Codrinschi $(31,5 \%)$.

Sinteza datelor experimentale privind influenţa soiurilor producătoare de struguri şi a soiurilor de portaltoi asupra rezultatelor randamentului materialului săditor altoit sunt prezentate în tabelele 3 şi 4 . Soiurile producătoare de struguri Fetească neagră şi Fetească regală au exercitat o influenţă pozitivă sub forma unui spor de viţe altoite, respectiv de 20,4 şi 16,6\%, faţă de martor.

Cât priveşte influenţa soiurilor de portaltoi asupra randamentului viţelor altoite, s-a constatat că numai soiul de portaltoi Riparia x Rupestris 101-14 a exercitat o influenţă pozitivă sub forma unui spor de material săditor altoit de 21,6\%, faţă de martor, pe când

Datele obținute în urma clasării vițelor din soiurile autohtone Vitis vinifera altoite pe diferite soiuri de portaltoi (SRL „Élvitis-Com " și SRL „Retrodex”, media 2015-2020)

\begin{tabular}{|c|c|c|c|c|}
\hline \multirow{2}{*}{ Soiul altoi } & \multicolumn{3}{|c|}{ Soiul portaltoi } & \multirow{2}{*}{ Media } \\
\hline & $101-14$ & Kober 5BB & SO4 & \\
\hline \multicolumn{5}{|c|}{ 1. Randamentul în viţe standard, \% } \\
\hline Fetească neagră & 56,3 & 41,1 & 46,2 & 47,9 \\
\hline Fetească regală & 43,6 & 54,9 & 40,8 & 46,4 \\
\hline Rară neagră & 35,4 & 27,6 & 36,8 & 33,3 \\
\hline Codrinschi & 58,3 & 22,1 & 14,0 & 31,5 \\
\hline Media & 48,4 & 36,4 & 34,5 & 39,8 \\
\hline \multicolumn{5}{|c|}{ 2. Diametrul cordiţei principale, $\mathrm{mm}$} \\
\hline Fetească neagră & 5,8 & 5,8 & 5,3 & 5,6 \\
\hline Fetească regală & 5,9 & 6,1 & 6,3 & 6,1 \\
\hline Rară neagră & 6,4 & 5,8 & 5,6 & 5,9 \\
\hline Codrinschi & 5,5 & 7,6 & 5,1 & 6,1 \\
\hline Media & 5,9 & 6,3 & 5,6 & 5,9 \\
\hline \multicolumn{5}{|c|}{ 3. Numărul total de rădăcini pe o viţă } \\
\hline Fetească neagră & 20,2 & 16,1 & 14,3 & 16,9 \\
\hline Fetească regală & 18,4 & 17,4 & 15,9 & 17,2 \\
\hline Rară neagră & 19,6 & 14,9 & 14,8 & 16,4 \\
\hline Codrinschi & 16,6 & 17,2 & 13,4 & 15,7 \\
\hline Media & 18,7 & 16,4 & 14,6 & 16,6 \\
\hline
\end{tabular}


soiurile Berlandieri x Riparia Kober 5BB şi Berlandieri x Riparia SO4 au avut o influenţă negativă faţă de randamentul materialului săditor din varianta martor, respectiv prin valori de 8,5 şi $13,3 \%$.

Rezultatele determinării calităţii materialului săditor din variantele experienţei, exprimate prin numărul de rădăcini şi grosimea lor, în medie pe o viţă altoită, sunt prezentate în tabelul 2.

Soiul de portaltoi a influenţat, într-o anumită măsură, grosimea cordiţei principale a viţelor din soiurile producătoare de struguri luate în cercetare. Diametrul cordiţei din soiurile Rară neagră $(6,4 \mathrm{~mm})$ şi Fetească neagră $(5,8 \mathrm{~mm})$ a fost superior pe viţele altoite pe portaltoiul 101-14, iar cele din soiul Fetească regală $(6,3 \mathrm{~mm})$ - pe portaltoiul SO4, şi numai viţele din soiul Codrinschi $(7,6 \mathrm{~mm})$ a fost superior pe portaltoiul Kober 5BB.

Cât priveşte numărul total de rădăcini, în medie pe o viţă, la toate soiurile autohtone luate în cercetare a fost mai mare în cazul altoirii pe portaltoiul 101-14 (18,7 mm), urmat de Kober 5BB (16,4 mm), apoi de SO4 (14,6 mm).

$\mathrm{Pe}$ baza cercetărilor efectuate vor fi elaborate recomandări privind alegerea celor mai corespunzătoare soiuri de portaltoi pentru altoirea soiurilor şi clonelor de soiuri autohtone valoroase producătoare de struguri (afinitatea de altoire), pentru a obţine cel mai înalt randament de material săditor din categoriile biologice superioare („Prebază”, „Bază”), destinat înfiinţării în unităţile de preînmulţire şi în unităţile pepinieriste a plantaţiilor de altoi şi portaltoi. Aceasta va contribui considerabil la modernizarea viticulturii prin accelerarea producerii materialului săditor valoros şi înfiinţarea plantaţiilor de vii moderne, longevive, care vor asigura un potenţial înalt şi stabil de struguri.

E de remarcat faptul că cele mai corespunzătoare soiuri de portaltoi care au cea mai bună afinitate de altoire nu întotdeauna pot fi cele mai productive pentru afinitatea de producţie. Mai cu seamă că plantaţiile de vii sunt înfiinţate în zone cu diferite condiţii pedoclimatice, iar soiurile de portaltoi pe care-s altoiţi butucii reacţionează în mod diferit. Pentru determinarea potenţialului productiv şi oenologic (afinitatea de producţie) al fiecărui soi producător de struguri, în funcţie de încărcătura butucilor şi soiul de portaltoi, în regiunea de sud a R. Moldova, SRL „Terra Vitis” a fost montat un lot experimental. Cercetările au fost inițiate în anul 2021.

\section{CONCLUZII}

În urma cercetărilor efectuate privind stabilirea afinităţii de altoire a soiurilor autohtone Vitis vinifera în interacţiune cu principalele soiuri de portaltoi recomandate pentru $\mathrm{R}$. Moldova, se desprind următoarele concluzii:

1. Numărul butaşilor altoiţi cu calus circular la punctul de altoire, la toate soiurile producătoare de struguri luate în cercetare, a fost mai mare în cazul altoirii lor pe portaltoiul Riparia x Rupestris 101-14 $(97,2 \%)$, urmat de Berlandieri x Riparia Kober 5BB $(88,4 \%)$, iar pe portaltoiul Berlandieri x Riparia SO4, indicele de calusare a fost mai mic $(87,9 \%)$.

\section{Sinteza rezultatelor privind influența soiurilor producătoare de struguri asupra randamentului vițelor altóite pe diferite soiuri de portaltoi}

\begin{tabular}{|c|l|c|c|c|}
\hline $\begin{array}{c}\text { Nr. } \\
\text { d/o }\end{array}$ & \multicolumn{1}{|c|}{$\begin{array}{c}\text { Soiurile producătoare de } \\
\text { struguri }\end{array}$} & $\begin{array}{c}\text { Randamentul viţelor } \\
\text { altoite, } \\
\%\end{array}$ & $\begin{array}{c}\text { Diferenţe, } \\
+/-\end{array}$ & $\begin{array}{c}\text { Procente faţă de } \\
\text { media generală }\end{array}$ \\
\hline 1. & Fetească neagră & 47,9 & 8,1 & 120,4 \\
\hline 2. & Fetească regală & 46,4 & 6,6 & 116,6 \\
\hline 3. & Rară neagră & 33,3 & $-6,5$ & 83,7 \\
\hline 4. & Codrinschi & 31,5 & $-8,3$ & 79,0 \\
\hline 5. & Media generală (martor) & 39,8 & 0,0 & 100 \\
\hline
\end{tabular}

Sinteza rezultatelor privind influența soiurilor de portaltoi asupra randamentului vițelor altoite producătoare de struguri

\begin{tabular}{|c|l|c|c|c|}
\hline $\begin{array}{c}\text { Nr. } \\
\text { d/o }\end{array}$ & Soiurile producătoare de struguri & $\begin{array}{c}\text { Randamentul } \\
\text { viţelor altoite, } \\
\%\end{array}$ & $\begin{array}{c}\text { Diferenţe, } \\
+/ \text { - }\end{array}$ & $\begin{array}{c}\text { Procente faţă de } \\
\text { media generală }\end{array}$ \\
\hline 1. & Riparia x Rupestris 101-14 & 48,4 & 8,6 & 121,6 \\
\hline 2. & Berlandieri x Riparia Kober 5BB & 36,4 & $-3,4$ & 91,5 \\
\hline 3. & Berlandieri x Riparia SO4 & 34,5 & $-5,3$ & 85,3 \\
\hline 4. & Media generală (martor) & 39,8 & 00 & 100 \\
\hline
\end{tabular}


2. Soiul de portaltoi determină durata perioadei de pornire în creştere a ochilor de pe altoiul butaşilor altoiţi în timpul forţării, călirii şi plantării în şcoala de viţe. În primul rând pornesc în creştere ochii de pe altoiul butaşilor altoiţi pe portaltoiul 101-14, urmat, peste 3-4 zile, pe portaltoiul Kober 5BB, şi numai peste 2-3 zile după pornirea în creştere a ochilor de pe butaşii altoiţi pe Kober 5BB pornesc în creştere şi ochii de pe cei altoiţi pe SO4.

3. Soiul de portaltoi determină durata perioadei de apariţie (formare) a rădăcinilor. La toate soiurile nobile, rădăcinile apar în primul rând la baza butaşilor altoiţi pe soiul de portaltoi 101-14, urmat, peste 5-7 zile, pe butaşii altoiţi pe Kober 5BB, iar cel mai târziu - pe cei altoiţi pe SO4.

4. Cel mai înalt randament de material săditor standard la soiurile Codrinschi şi Fetească neagră s-a înregistrat în cazul altoirii lor pe portaltoiul 101-14, iar la soiul Fetească regală - pe portaltoiul Kober 5BB.

Notă: Cercetările privind stabilirea afinității de altoire a 4 soiuri autohtone de viță-de-vie producătoare de struguri pentru vin altoite pe 3 soiuri de portaltoi au fost efectuate în decursul anilor 2015-2020.

\section{BIBLIOGRAFIE}

1. Constantinescu Gh., Oşlobeanu M., Poenarul I., Vodarici, Emilia, Mujdaba F. Studiul comparativ al caracteristicilor de productivitate la principalele soiuri de viţă roditoare din podgoria Murfatlar. Analele Institutului de Cercetări Agronomice, XXVI, 1958. Anexa viticultură, pomicultură şi legumicultură.

2. Constantinescu Gh., Văleanu L., Poenarul I. Portaltoii folosiţi în viticultura din RPR şi influenţa lor asupra prinderii la altoire, producţiei şi longevităţii plantaţiilor. Buletinul ştiinţific al Academiei RPR, vol. VIII, 1966.

3. Dalmasso G. Nuove veduta suli affinita d'innesto in Viticultura, Firenze, 1950.

4. Grecu V. Îndrumătorul pepinieristului viticol. Bucureşti, editura Ceres, 1980, 438 p.

5. Huglin P. Recherches sur les bourgeons de la vigne: initiation florale et developpement vegetatif. Anales de L'Institut National de la Recherche Agronomique. Seria B. Anales de L'amelioration des plantes, nr. 2, 1958.
6. Малтабар Л.М. Требования, предъявляемые к выбору подвойных филлоксероустойчивых сортов винограда и подвойно-привойных пар. Вкн. Обеспечение устойчивого производства виноградо-винодельческой отрасли на основе современных достижений науки, Анапа, 2010, с. 224-231.

7. Martin T., Oprea D., Dvornic V., Pomohaci N., Georgescu, Magdalena. Interacţiunea altoi/portaltoi şi implicaţiile sale în practica viticolă. Lucrări ştiinţifice. Volum omagial la a 25-a aniversare a Facultăţii de Horticultură, Bucureşti, 1973.

8. Stoian M., Petrescu M., Dragunescu, Anca, Tomescu M., Nedelcu Gh. Stabilirea afinităţii de altoire şi producţie a unor elite de portaltoi în interacţiune cu soiurile Fetească neagră, Burgunt mare şi Muscat de Poskei în condiţiile Centrului Viticol „Valea Călugărească”. Analele Institutului de Cercetare-Dezvoltare pentru Viticultură şi Vinificaţie „Valea Călugărească”, vol. XVII, 2004, p.79-86.

9. Stoian M., Cazacu M., Porumb, Roxana, Tomescu M., Chiviu, Paula. Combinaţii privind afinitatea de altoire şi producţie a unor elite de Merlot în interacţiune $\mathrm{cu}$ principalele soiuri de portaltoi recomandate pentru Centrul Viticol „Valea Călugărească”. Analele Institutului de Cercetare-Dezvoltare pentru Viticultură şi Vinificaţie „Valea Călugărească", vol. XVII, 2004, p. 70-78.

10. Taran N., Ungureanu S., Roşca O., Soldatenco, Eugenia, Vasiucovici, Svetlana. Potenţialul productiv şi oenologic al soiurilor Aligote şi Riesling de Rhin, altoite pe diferite soiuri de portaltoi. În: Pomicultura, Viticultura şi Vinificaţia, nr. 2, 2017, p. 3-7. ISSN 1857-3142

11. Ungureanu S. Selectarea celor mai bune soiuri de portaltoi. În: Viticultura şi Vinificaţia în Moldova, nr. 1 , 2007, p. 8-9.

12. Ungureanu S. Recomandări privind alegerea soiurilor de portaltoi pentru 8 soiuri clasice şi 10 soiuri de selecţie nouă. În: Pomicultura, Viticultura şi Vinificaţia, 2015, nr. 3, p. 24-28. ISSN 1857-3142.

13. Ungureanu S., Ceban V. Tehnologia producerii materialului săditor viticol. Chişinău, Tipografia AŞM, 2019, 456 p. 978-9975-62-451-1-2

14. Zimmerman I. Entwicklugshythmus der Rebenstorten und der Affinitat. In: Weinberg un Veller, nr. 5, 1959, p. $171-180$

RECENZIE ŞTIINȚIFICĂ - Vitalie CEBANU, doctor în știntie agricole.

Materialul a fost prezentat la 24.05.2021. 